\title{
Erratum to: Application of variable-temperature kinetic experiments to oxidative addition reactions of dimethylplatinum(II) complexes with alkyl halides
}

Fatemeh Niroomand Hosseini

Published online: 17 May 2014

(C) Springer International Publishing Switzerland 2014

Erratum to: Transition Met Chem (2013) 38:699-703 DOI 10.1007/s11243-013-9739-z

Because of a miscommunication during the editorial process S. Masoud Nabavizadeh was included as one of the authors in the original publication of this paper while in fact he is not.

The online version of the original article can be found under doi:10. 1007/s11243-013-9739-z.

F. Niroomand Hosseini $(\bowtie)$

Department of Chemistry, Shiraz Branch, Islamic Azad

University, 71993-37635 Shiraz, Iran

e-mail: niroomand55@hotmail.com; niroomand@iaushiraz.ac.ir 